\title{
The Bologna agreement is not suitable for medical ed- ucation: a German view
}

\author{
J. Pfeilschifter
}

\begin{abstract}
Summary
Central elements of the Bologna declaration have been implemented in a huge variety of curricula in humanities, social sciences, natural sciences and engineering sciences at German universities. Overall the results have been nothing less than disastrous. Surprisingly, this seems to be the perfect time for German universities to talk about introducing a curriculum that is fully compatible with the Bologna declaration for medical education as well. However, German medical education does not have problems the Bologna declaration is intended to solve, such as quality, mobility, internationalization and employability. It is already in the Post-Bologna age. (Pfeilschifter J. The Bologna agreement is not suitable for medical education: a German view. Netherlands Journal of Medical Education 2010;29(1)-37-41)
\end{abstract}

\section{Introduction}

Sick people need cures, healthy people do not and - taking chemotherapy as an example - what is beneficial to the sick may, in fact, be detrimental to those who are healthy. However, if one decides to start treatment, it is generally accepted that the illness must be diagnosed first. At least that is what we teach our medical students.

\section{Medical curriculum in Germany}

The current medical curriculum in Germany is alive but not in the best of health. For those engaged in it - be they students or teachers - the painful symptoms are evident. Medical schools are heavily overcrowded and understaffed - the average student-teacher ratio of 26 to 1 in Germany (and as much as 40 to 1 in Frankfurt!) is one of the worst among European countries (http://www.landkartehochschulmedizin.de). Despite its length (twelve semesters) the curriculum is packed full and has lost almost all traces of the academic freedom that used to be the hallmark of higher education in the days before 'Bologna'. Students complain about what they term 'theory overload' and are pressing for earlier and better integration of clinical and theoretical training. University teachers on the other hand deplore the ever increasing lack of indepth scientific education. So we seem to have a clear diagnosis of a potentially inflammatory disease: overload and a conflict of interest. The first problem might be treated by allocating more money and time to education. The second problem essentially the difference between schooling [Ausbildung] and education in the sense of developing students' intellectual faculties and powers [Bildung] is probably as old as the universities themselves, which have always taken upon themselves the dual task of training practitioners and nurturing original thinkers and innovators.

Sick yes, dying no! The medical education system is far from perfect but it is still in working order, even though we have reached - and partially transgressed - the limits of its capacity. Despite the over- 
loaded curriculum, there are very few (approximately $5 \%)^{1}$ dropouts, we certainly do not suffer from a lack of applicants (4.4 applications per university place) (http://www.zvs.de) and it is easy for students to switch between universities, with approximately one third of them gaining international experience, ${ }^{2}$ for instance by spending their 'practical year' in a foreign country. Moreover our graduates have few, if any, problems finding employment in Germany or abroad.

To keep inflammation in check and prevent the development of a chronic condition we need to find a cure for medical teaching. We need to resolve the appalling student-teacher ratio and we need to find a better way of integrating theoretical and practical training - without sacrificing science. As far as curricular issues are concerned, we have already started treatment and the 'Approbationsordnung' of 2002, which has been in place since October 2003 , certainly seems to be a step in the right direction. The first graduates of this reform are now 'on the market' and we wait with baited breath to see how they will fare. However, solid theoretical and practical training is teacher intensive and our good designs and intentions are continually undermined by unacceptable student-teacher ratios. As far as the 'capacity' or annual intake of medical schools is concerned, our only option is to continue to appeal to politics and alert politicians to our plight. After all it is politicians who, together with lawyers an idiosyncrasy of the German situation determine intake numbers and are responsible for the fact that theoretical and practical courses alike are regularly drowned in numbers. Indeed, the annual intake of the average German medical school is 383 students (for some it is over 800!) (http://www.landkarte-hochschulmedizin.de) - several times in excess of the intake of medical schools in our neighbouring EU countries.

A positive trend in modern medicine is to acknowledge that not all patients are created equal and the resulting strong impetus towards individualized medicine and treatment tailored to the specific needs of individual patients. Working against this trend, politicians decided to cure the ills of universities with a global and consequently rather inadequate pill: the Bologna process. On paper, the goals of the process may have some merit as they aim to create an attractive common European higher education area by standardizing academic degrees. This entails the introduction of a system of 'credits' (ECTS credits) quantifying 'academic workload' and it is expected to foster increased mobility and internationalization of academic staff and students, employability of academic graduates and life-long learning. Of course, it is also accompanied by an inevitable and complex bureaucracy of accreditation agencies, quality assurance and reporting systems.

In the original declaration (Bologna, 1999) the idea of a 'two-cycle system' was at the core of the curricular reforms. The first cycle - leading to a degree called 'bachelor' - was supposed to deliver 'employable' graduates. A second cycle - the 'master' - was meant for those interested and able to undertake advanced studies. In the most recent declarations, a third cycle has been added: the doctorate.

Outside medicine, the Bologna process and the curricular reorganizations it necessitated were initially met with subdued enthusiasm by both academic teachers and students. Now, 10 years on, even the German minister of science and education, Mrs. Annette Schavan, has had to admit the necessity to reform the reform. ${ }^{3}$ The measurable indicators we had hoped 
would hail the success of the Bologna process, such as mobility, employability, internationalization and dropout rates, all point at a deterioration of standards and failure. Many of our most respected intellectuals from the fields of the humanities and natural sciences have raised their voices in anger complaining about the destruction of academic values and abilities by the ECTS credit-driven drilling of bachelors and masters.

Inside German medicine, no one has really cared all that much about the Bologna reforms; we thought they were nothing to do with us; in fact, we have secretly gloated as we watched the credit counting struggles of our neighbouring faculties. However, as outlined in the current issue of Medical Education, pressure is mounting to apply the Bologna cure to medicine as well. At this point we clearly need to ask: why? Why should we implement bachelor's and master's degrees in medicine, why should we struggle with credits and accreditation agencies? Who is supposed to benefit from those reforms and how?

Let us take a look at the first cycle: the 'bachelor' or, more specifically, the 'bachelor of medicine'. Obviously, since it is a 'first cycle', it must be shortened to comply with the current 'single cycle' medical curriculum. And - that is the charm of the Bologna process - the workload required to obtain the degree can be specified in numbers: 180 ECTS points, corresponding to an 'academic workload' of three years or six semesters.

What will the bachelor of medicine be qualified to do? She or he may have basic medical knowledge but is barely employable and cannot be let loose on the unsuspecting public anywhere in Europe. Indeed, the mandatory EU guideline $2005 / 36$, section 2 , article 24,2 requires at least six years of theoretical and practical training to be eligible for qualification as a practising physician. The 'bachelor of medicine' is also no academic shortcut cure for potential dropouts from medical degree programmes - simply because such dropouts are very few. It has been argued that the bachelor of medicine might gain popularity among medical students, if they would take it as an opportunity to drift away into the non-curative branches of the field - a 'quitting bachelor', so to say - would that make sense? We argue that this is nonsense; given the current background of tight and expensive medical school capacities and the shortage of medical doctors, why should we encourage our students to quit before they have reached their and indeed our goal?

The 'entering bachelor' is another scenario we need to consider. $\mathrm{He}$ or she might be imagined as someone who has collected enough credits in some healthrelated discipline or other scientific field and is now striving to obtain a medical master's degree and qualify as a medical practitioner. Needless to say that - given the current background of limited capacity and more than enough regular applicants for medical school places - it makes little sense to encourage these career changers. In reality, such individuals would have to go back and study parts or essentially most of the medical bachelor programme in order to obtain the medical knowledge and skills required to enter the master programme.

A third type of bachelor, the 'bachelor en passant', is a qualification we already have. Our colleagues in Switzerland, Denmark and the Netherlands decided to award that degree to their third year medical students. Needless to say (see above) that the title is entirely useless to those who have gained it, as practically all medical students want to become doctors and continue directly with the master programme. In other words: the 'bachelor en 
passant' is more or less a cosmetic operation, which only pays lip service to the 'spirit of Bologna'. This interim solution is not a new one, however. We used to award our students the title 'candidatus medicinae' after their first state exam, which was just as useful and actually sounded better than 'bachelor'.

The Bologna reforms envisage two more cycles of master and Ph.D. programmes. The 'master' is basically what we already have, albeit not the 'master of 240 or more ECTS credits', but medical doctors, well equipped to face the challenges of medical practice after they have passed the rigorous second state exam. After passing this exam, which, as mentioned above, the majority normally do, medical graduates are employable and internationally searched after.

The third cycle, the doctorate degree, we also already have, and fortunately - I am almost inclined to say - the demands of that degree are highly variable. Yes, some medical dissertations are of deplorable quality and the academic title may serve its carrier no other useful purpose than to act as a helpful placebo in contacts with patients. There are of course exceptions as some dissertations contain cutting-edge science, and it is actually here, in the wide open and relatively little regulated field of dissertations in medicine, that some medical students find their scientific destination or - vice versa - that students from other faculties find their way into medicine. The latter gain the doctor's title but do not practise medicine but rather become teachers and researchers. Thus, all in all, the existing system contains extremely valuable remnants of academic freedom in medicine and any attempt to 'standardize' and "quantify" that third cycle will only produce one thing: the well known mediocrity of Bologna.

\section{In summary}

There are clearly several problems in medical education in Germany, the most severe and urgent ones being the high annual intake of students and a lack of individual teaching. However, there are also several problems we do not have, such as quality, mobility, internationalization and employability. Viewed against that background, Bologna is not the remedy, but the illness. It is a mass-produced cure for a disease we do not have. It is a therapy without a diagnosis. It is medical malpractice, if not to say quackery, which certainly is irresponsible.

\section{References}

1. Heublein U, Schmelzer R, Sommer D, Wank J. Die Entwicklung der Schwund- und Studienabbruchquoten an den deutschen Hochschulen. Statistische Berechnungen auf der Basis des Absolventenjahrgangs 2006. (HIS): Projektbericht Mai 2008. Hannover: HIS Hochschul-Informations-System GmbH; 2008. Zugänglich unter: http://www.his.de/pdf/21/his-projektbericht-studienabbruch_2.pdf. [Trends in attrition and dropout rates in German higer education. Statistical analysis based on the class graduating in 2006 . Project report May 2008].

2. DAAD/BMBF. Internationale Mobilität im Studium 2009. Wiederholungsuntersuchung zu studienbezogenen Aufenthalten deutscher Studierender in anderen Ländern. Hannover: HIS Hochschul-Informations-System GmbH; 2009. Zugänglich unter: http://www.his.de/pdf/21/Konferenz_2009-05-14.pdf. [International mobility of students 2009. Repeat investigation of German students going abroad for their studies. Higer Education Information System].

3. Bundesministerium für Bildung und Forschung. Pressemitteilung vom 7. Juli 2009. Berlin: Bundesministerium für Bildung und Forschung; 2009. [Federal Ministry of Education and Research. Press announcement 7 July 2009].

The author

T.J. Pfeilschifter PhD, is professor and dean of the Faculty of Medicine and Chairman of the Institute of Pharmacology and Toxicology, Goethe-University Frankfurt, Germany. 
Correspondence

Theodor J. Pfeilschifter, dean of Faculty of MedicineGoethe-University, Theodor-Stern-Kai 7, D-60590

Frankfurt am Main. Tel.: 0049696301 6010;

E-mail:pfeilschifter@em.uni-frankfurt.de

No potential conflict of interest relevant to this article was reported 